\title{
PERIFERIA DE UNA NARRATIVA NACIONAL EN UNA DÉCADA
}

\author{
POR \\ José Delgado Costa \\ Ohio University
}

La narrativa puertorriqueña publicada durante la pasada década de los ochenta aviene básicamente dos corrientes filosóficas intercambiables. Por un lado, se aglutinan metáforas culturales con el propósito de desnudar al sistema de símbolos que se ha usado para representar y mitificar dicha cultura. Por el otro, se desprende de esa narrativa un esfuerzo por recoger la sofocante confrontación diaria surgida de la veloz transformación económica en los últimos cincuenta años. Ambas tendencias se abastecen de un imperativo espíritu crítico.

No se puede hablar, sin embargo, de una literatura puertorriqueña de la década de los ochenta sin antes hacer mención de En cuerpo de camisa (San Juan: Ediciones Lugar, 1966), al igual que la novela La guaracha del Macho Camacho (Buenos Aires: Ediciones de la Flor, 1976) de Luis Rafael Sánchez. Estas dos publicaciones establecen las nuevas pautas de la narrativa boricua. Desde su publicación, tanto los personajes marginados como los del proletariado, así como la dimensión psíquica y lingüística de éstos se convierten en nota obligatoria para los nuevos autores. Desde entonces, la mayoría de las nuevas narraciones han venido abordando temas semejantes con variaciones de la misma estrategia narrativa. La realidad de las letras insulares adopta una posición donde, curiosamente, las características del habla de los personajes se convierten en receta literaria por donde se filtran tanto su identidad nacional como sus universales conflictos humanos. Aunque su individualidad humana es central en la mayoría de las narraciones, muchos de estos personajes se deleitan en su acento y usos populares del lenguaje, articulando de esa forma su múltiple universalidad. Desde Sánchez, está harto claro que para ser puertorriqueño o entenderlo, no podemos ser monolíticos sino eclécticos, aun y cuando superficialmente parezca que no hagamos tal ejercicio. Los trabajos de ficción publicados por autores boricuas en la década de los ochenta reflejan una racionalización variada de una agitada y sedentaria, feliz y confusa, cosmopolita y ensimismada, heroica y mediocre, enajenada y enajenante situación humana.

La narrativa puertorriqueña de la década de los ochenta presenta en sus artificios artísticos a una sociedad en crisis. La creciente carga de problemas, mayormente urbanos, se explora desde distintas sensibilidades. Con recurrentes temas como el inagotable acoso por la búsqueda de bienestares materiales y las subsiguientes dinámicas interpersonales y dependencias económicas que esa situación suscita, pasando por un casi inaguantable 
tormento propagandístico, al igual que una penetrante revalorización de valores humanos importunados por una crasa falta de comunicación y llegando al reemplazo de la vieja línea burguesa dominante por otra industrial, la nueva narrativa puertorriqueña sugiere que la vida moderna en esa isla sufre del absurdo.

A su vez, el actual status político está en pugna con la identidad cultural. Ésta, al mismo tiempo, acecha al pasado y al presente históricos tratando de auscultar y extraer de él la esencia del espíritu puertorriqueño. La conciencia psicológica del individuo y su expresión lingüística, así como la denuncia caracterizada por la confusión social, se manifiestan entre el arte y el compromiso. Decir, sin embargo, que la más reciente producción literaria puertorriqueña se alimenta más que nada del compromiso político, sería desfavorecer esa realidad. Aunque domina el tema de Puerto Rico como problema (las clases sociales, los marginados, la política), ahora la psiquis del personaje, su sexualidad, la historia de su familia, la de su país y la de su hemisferio conviven en una literatura que se auto-reconoce, insisto, primeramente y sobre todo, como artificio artístico. Este hecho es importante porque una vez que la literatura cesó de verse como portadora de verdades culturales, se amplió el diálogo artístico y crítico en la isla. Es decir, la literatura se entiende ahora como otra industria que no tiene todas las soluciones ni dice todas las verdades. Lo que sí existe, sin embargo, es una estrecha relación entre la vivencia de una sociedad que parece estar predispuesta teatralmente a ser su propio público, y la conciencia artística que suple a esa comunidad de la validez necesaria para que emita su raíz más honda.

Las dramáticas transformaciones económicas y sociales de los últimos cincuenta años han calado en todos los niveles de esa comunidad causando una realidad de un pathos esquizofrénico. El tema del miedo a perder la identidad cultural y la crítica a la burgesía asimilista norteamericana se ve muy claro en la novela Mi mamá me ama (Barcelona: Seix Barral,1981) de Emilio Díaz Varcárcel. El título, inuendo incestuoso, sugiere que el ideal materno, léase la cultura propia, produce atrocidades que giran alrededor del sistema asimilista. La trama desarrolla la historia de un joven que escribe, a manera de diario, el borrador para un trabajo de investigación de tipo sociológico sobre distintos grupos en Puerto Rico. A lo largo de la novela, lo puertorriqueño se desvalora irónicamente llegándose hasta el absurdo. La familia del joven, por ejemplo, en puro verano tropical enciende el aire acondicionado a todo dar y el padre, con bufanda y fumando pipa, enciende una chimenea en la casa. La cosa es recrear el mundo norteamericano lo más fielmente posible. No en balde este tipo de producción narrativa, que insiste en temas ya tratados con anterioridad, en la nueva narrativa boricua se despuntan otros senderos. Es sumamente estimulante leer novelas que tratan, por ejemplo, de la sexualidad de la vejez como es el caso con La última noche que pasé contigo (Barcelona: Editorial Tusquets, 1991 [escrita en los 80]), de Mayra Montero. Esta novela, no sólo nos lleva de viaje en crucero por el Caribe, ambientando así su trama con lo antillano, sino que además nos adentra al mundo sensual y erótico de las personas maduras.

También producen incitación cuentos y novelas de temas variados como el feminismo y la historiografía familiar o nacional, los cuales están al día o hacen vanguardia en ese frente. Por ejemplo, Virgenes y mártires (Río Piedras: Editorial Antillana, 1981), de gran éxito comercial, escrito en colaboración entre Ana Lydia Vega y Carmen Lugo Fillipi utilizan con mordaz humor la descodificación de la autoridad masculina. Desenmascarando con ironía y sutileza el machismo y el sistema colonial, se desnuda el endeble carácter de 
éstos. En muchos de los relatos de ese libro, la mujer asume el papel central representándose a través de ella la conciencia fundamental de la realidad humana, especialmente en el ámbito de la política sexual y nacional. Es una colección de cuentos cuya crítica no condena ciegamente, sino que inteligentemente optimista, exige cambios sociales y políticos. Igualmente, Maldito amor (México: Joaquín Mortíz, 1986) de Rosario Ferré, desmitifica paródicamente, bajo su lupa histórica, la conciencia patriarcal de los ricos hacendados isleños de finales del siglo XIX. Esta novela corta con tres narraciones largas articula el sexismo y el clasicismo del Puerto Rico en transición a finales de siglo XIX. Asimismo, un texto como Encancaranublado (La Habana: Casa de las Américas, 1982) de Ana Lydia Vega, enuncia con humor irónico la problemática racial y económica, no sólo de la isla de Puerto Rico, sino de todo el Caribe.

Otras narraciones optan por evocar la época de la colonización insular ofreciéndole suficientes giros y trastornos barrocos a ésta para crear un peculiar "lo que no fue y pudo haber sido". Así lo hace la novela La noche oscura del niño Avilés (Río Piedras: Ediciones Huracán, 984) de Edgardo Rodríguez Juliá. Con un toque estilístico de crónica, la novela se recrea en el pasado de una ciudad mítica cercana a San Juan llamada Nueva Venecia. Conocida a lo largo y a lo ancho de la región como ciudad maldita, la narración nos adentra por libertinos, diabólicos y mágicos sucesos del lugar para crear sus propios mitos, realidades y pesadillas.

También adueñándose del pasado para revisarlo, pero más específicamente por décadas y con núcleos familiares que sirven de eje para revalorar el tránsito de generaciones, al igual que con la utilización del collage para referirse a fuentes históricas y literarias, Puertorriqueños. Album de la sagrada familia puertorriqueña (Madrid: Playor, 1988) también de Edgardo Rodríguez Juliá, destaca el rápido proceso de transformación sufrido en los últimos cincuenta años. De la misma manera, Felices días tío Sergio (Río Piedras: Editorial Antillana, 1986) de Magali García Ramis, explora el vivir cotidiano de la clase media. García Ramis, a través de la visión infantil, critica ciertas características de la colectividad puertorriqueña como la politiquería, el consumismo, el conservadurismo y la falsedad. Adueñándose del tema de la familia urbana, los seis relatos largos que componen Cierta inevitable muerte (Buenos Aires: Ediciones de la Flor, 1988) de Edgardo Sanabria Santaliz, circundan entre las generaciones de los cincuenta y sesenta para explorar los temas de la niñez, la juventud y la vejez y cómo, con la muerte siempre achechando, la idea de familia sobrevive dentro de su torbellino de realidades penosas.

Otras narraciones optan por lanzarse a la calle cual reportero y fotógrafo "de toda la familia puertorriqueña" y con una modalidad de vaivén coloquial recogen la expresión humana que parece explicarse a sí misma entre lo festivo y lo trágico. Así lo demuestran las sagaces crónicas de Edgardo Rodríguez Juliá encuadernadas en tres títulos: Las tribulaciones de Jonás (Río Piedras: Ediciones Huracán,1981), El entierro de Cortijo (Río Piedras: Ediciones Huracán, 1983), y Una noche con Iris Chacón (Río Piedras: Editorial Antillana, 1986). Igualmente, la novela Vive y vacila (Buenos Aires: Ediciones de la Flor, 1986) del hasta entonces cuentista Juan Antonio Ramos, se orienta hacia el lenguaje popular y lo irreverente para revelar, saltando del presente al pasado y del pasado al presente, las intrascendencias sociales y la soledad individual.

Al mismo tiempo, otras narraciones buscan y encuentran el hilo conductor que hermana al puertorriqueño con todo lo hispanoamericano. Así lo demuestra La importancia 
de llamarse Daniel Santos (Hanover: Ediciones del Norte, 1988) de Luis Rafael Sáncez. En ésta, su segunda novela, se nos presenta al mitificado cantante de boleros como fondo musical que sirve de embudo en una estrategia discursiva que trata de producir la summa, tanto de una nacionalidad como de una identidad hispanoamericana, en Puerto Rico. Como el cantante, el país ha internalizado fragmentariamente a muchas otras culturas. También, ha contribuido al dote mítico hispanoamericano. Sánchez recoge los muchos pedazos que forman el carácter caribeño y los empata conflictivamente con la evaluación moral que la clase burguesa le ha proporcionado a la cultura popular. Otro libro con sabor a experiencia latinoamericana, pero esta vez de cuentos, es Las caricias del tigre (México: Joaquín Mortiz, 1984) de José Luis González. Los tres cuentos de diversas longitudes que componen al texto giran, tanto alrededor de la experiencia peregrina latinoamericana por las grandes capitales del extranjero: Praga, París y Nueva York, como alrededor de un pasado aventurero estudiantil artístico, plasmado de privaciones económicas y visto en el presente con sabiduría, pero teniendo siempre presente que aquel pasado no dejó de ser pleno y portentoso en su momento.

La actividad literaria puertorriqueña actual se encuentra en muy buena salud y no por gracia divina sino porque sus narradores han sabido entrenarse y manterse en forma. La difusión y respetabilidad de una literatura que se escribe "en puertorriqueño", (término acuñado por el crítico Efraín Barradas y que es una mezcla de lenguaje culto y popular), no debe extrañar a nadie. El hecho de que esos narradores se formen dentro de un ambiente dual: tanto provincial como cosmopolita, simpático y antipático, cómodo y áspero, favorecido y desprestigiado, y que esa realidad dual es básicamente la diaria modalidad de una cultura independiente y una subcultura que acecha, colocan al autor puertorriqueño en la envidiable posición de que su ubicación humana dentro del globo está en conflicto. Digo envidiable porque aunque todavía se hable de que muchos de los asedios literarios, sean éstos creativos o críticos, enfaticen el carácter de la identidad o el tema sociopolítico, las narraciones planteadas por los autores que despuntan están hechas, repito, por medio de una conciencia que se sabe, primero que nada, instrumento artístico. Similarmente, la sobrevivencia cultural no se ve, ni tampoco se percibe en un distante futuro, como moribunda, sino que es todo lo contrario. La robusta sapiencia cultural autóctona cuenta con una fuerte tradición. La extinción cultural no es la cuestión. Asimismo, el hecho de que varios autores en Puerto Rico hayan contribuido a la feroz marcha de desarrollos estilísticos en distintas esferas del ambiente literario fuera de la isla corrobora la potencia de su dinamismo artístico. Autores de la talla de Luis Rafael Sánchez, Rosario Ferré, Edgardo Rodríguez Juliá y Ana Lydia Vega han venido despuntando como voces pertenecientes al canon de la literatura hispanoamericana. Aprovecho la ocasión, sin embargo, para ofrecer una lista parcial de autores, de quienes injustamente no profundizo al igual que para ofrecer una lista de títulos significativos dentro y fuera del ámbito insular que, mayormente por espacio, sólo me limito a mencionar: Infiernos privados (Río Piedras: Editorial Cultural, 1986) del copioso y siempre cambiante novelista Enrique Laguerre, Impacto súbito (Río Piedras: Ediciones de la sierra, 1985) del cuentista Héctor Meléndez, Diarios robados (Buenos Aires: Ediciones de la Flor, 1982), de la cuentista Carmen Valle, Hilando mortajas (Río Piedras: Editorial Antillana, 1983), de Juan Antonio Ramos, Pasión de historia y otras historias de pasión (Buenos Aires: Ediciones de la Flor, 1987), de Ana Lydia Vega, Dicen 
que de noche tú no duermes (Río Piedras: Editorial Cultural, 1985), del novelista Emilio Díaz Valcárcel, Veintitrés y una tortuga (1981), y La trenza de la hermosa luna (1987), de la novelista Mayra Montero, El más azul de todos tus príncipes (1981) del novelista Edgardo Jusino Campos, Cuentos de aquí, de alláy de más de allá (1984) y Mujeres transplantadas (1989) de la cuentista Julia L. Ortiz, Nosotras ... como siempre (1984) de la cuentista Aracelis Nieves Maysonet, Las meninas de Avignon en Orgaz (1986), del novelista Ángel M. Encarnación, Porque hay silencio (1989), de la novelista Alba Nydia Ambert, La mitad de un dia (1989) de Ana María Delgado, Porque nos queremos tanto (1989) de la cuentista Olga Nolla y, de Rosario Ferré, dos títulos: Los cuentos de Juan Bobo (Río Piedras: Ediciones Huracán, 1981), y Sonatinas (Ediciones Huracán, 1989).

No importa cuál sea el paradero final de la ya literariamente raída situación política isleña, los narradores puertorriqueños tienen en sus manos una de las mejores, aunque no nueva pero me atrevo a decir modélica, comedias humanas. La cantidad de posibilidades literarias que de esa situación se desprenden, cosa que se ha venido haciendo inteligentemente, ya se evidencia alegremente en el presente de la literatura hispanoamericana. Si de Cuba se aprendió y se apreció el experimento socialista hecho literatura, de Puerto Rico se podrían aprender cuantiosos inuendos de la nueva situación global. El mundo, para bien o para mal, ya vive esa realidad. Homogéneos unos y heterogéneos otros, los nuevos narradores puertorriqueños son básicamente fieles a la plataforma política de la independencia. Esa condición, por su parte, ha creado conflictos con los narradores no independentistas que se quejan del monopolio cultural que supuestamente ejercen los narradores independentistas. Las obras de los más nuevos jamás abandonan la acusación política y social, pero ahora existe más escepticismo. La decadencia de los valores dominantes de raíces decimonónicas, por ejemplo, se reevalúan en la agresión cultural en que vive el país. En otras palabras, lo que José Luis González una vez tildó de "plebeyismo", toma el papel central en la elaboración literaria del carácter nacional. Además, una bienaventurada ola feminista le hace frente a la opresión machista; de la misma forma en que se resiste la opresión sexista contra la homosexualidad. Al mismo tiempo, la idea de crear literariamente una identificación común con el mundo latinoamericano $\mathrm{y}$, especialmente, con el caribeño, se va cementando y extendiendo.

La literatura puertorriqueña actual merece un más profundo acercamiento. Se les debe aplaudir a los creadores puertorriqueños que, pese al torrente cultural proveniente de los Estados Unidos dada su situación política con éste, han mantenido como partícipes del macromundo de las letras, una independencia literaria que se sabe asociar con las tendencias contemporáneas y más aún, crear las suyas.

\section{Obras CONSULtadas}

Barradas, Efraín. "La necesaria innovación de Ana Lydia Vega: preámbulo para lectores vírgenes." Revista Iberoamericana 132-133 (1985), 547-556.

Para leer en puertorriqueño: acercamiento a la obra de Luis Rafael Sánchez. Río Piedras: Ediciones Cultural, 1981.

Apalabramiento. Hanover: Ediciones del Norte, 1983. 
Fernández Olmos, Margarita. "Luis Rafael Sánchez and RosarioFerré: Sexual Politics and Contemporary Puerto Rican Narrative". Hispania 1, vol. 70 (marzo 1987), 40-46. "Desde una perspectiva femenina: la cuentística de Rosario Ferré y Ana Lydia Vega". Homines 2, vol. 8 (junio 1984-85), 303-311

Foster, David William (ed). "Puerto Rico". Handbook of Latin American Literature. Aníbal González (New York: Garland Publishing, 1987), 487-515.

Sola, María M. Aqui cuentan las mujeres. Río Piedras: Ediciones Huracán, 1990.

Ortega, Julio. "Conversaciones en San Juan". Cuadernos Americanos 3, vol. CCLX (mayo-junio 1985), 50-63.

Reapropiaciones: ensayos sobre literatura puertorriqueña actual. Río Piedras: EDUPR, 1991.

Rivera de Alvarez, Josefina. Historia de la literatura puertorriqueña. Santurce: Departamento de Instrucción Pública, 1969.

Literatura puertorriqueña: su proceso en el tiempo. Madrid: Ediciones Partenón, 1983.

Ruiz Barrionuevo, Carmen. "Rodríguez Juliá: una ojeada sobre Puerto Rico, entre la burla y la compasión". Revista Iberoamericana 159 (abril-junio 1992), 367-378.

Santos Silva, Loreina. "Cuatro selecciones por una peseta: patrones de sexismo machista". Revista/Review Interamericana 4, vol. 12 (Winter 1982-1983), 515-520.

Vega Carney, Carmen. "El amor como discurso político en Ana Lydia Vega y Rosario Ferré". Letras Femeninas 1-2, vol. 7 (Spring-Fall 1991), 77-87. 